\title{
Palliative treatment efficacy of glucose inhibition combined with chemotherapy for non-small cell lung cancer with widespread bone and brain metastases: A case report
}

\author{
YONGPING LIU ${ }^{1}$, YAPING ZHANG $^{1}$, XIBAO MAO $^{2}$, QIUFENG $^{1}{ }^{1}$, MING ZHU $^{1}$, \\ CHANGSONG ZHANG ${ }^{1}$, XUEFENG PAN $^{1}$ and YANG LING ${ }^{1}$ \\ ${ }^{1}$ Clinical Oncology Laboratory; ${ }^{2}$ Department of Nuclear Medicine, Changzhou Tumor Hospital \\ Affiliated to Soochow University, Changzhou, Jiangsu 213032, P.R. China
}

Received September 15, 2017; Accepted September 22, 2017

DOI: $10.3892 /$ br.2017.1008

\begin{abstract}
Otto Warburg observed in 1924 that cancer cells were dependent exclusively on glycolysis for the production of energy even in the presence of oxygen (the 'Warburg effect'). Consequently, cancer cells require $\sim 19$ times more glucose uptake to obtain equivalent amounts of energy as normal cells. The Warburg effect is the scientific basis for positron emission tomography (PET), which has markedly improved cancer detection. During chemotherapy, cancer cells may upregulate their expression of multi-drug resistance proteins and ultimately cause treatment failure. As multi-drug resistance proteins require energy to operate, the present report evaluated the potential clinical efficacy of lowering blood glucose with insulin during chemotherapy for a patient with advanced pulmonary adenocarcinoma with multiple metastases. A 64-year-old male was admitted to the Department of Medical Oncology at Changzhou Tumor Hospital (Changzhou, China) due to an irritating cough and multiple bone pain. PET/computed tomography (CT) with F-18 fluorodeoxy glucose $\left({ }^{18} \mathrm{~F}-\mathrm{FDG}\right)$ identified multiple hypermetabolic foci in the right hilum, right upper lung, shoulder blades, thoracic vertebrae, lumbar, sacrum, bilateral iliac crest and pelvis. Additionally, magnetic resonance imaging detected multiple metastases in the brain. The patient received 56 repeat treatments with insulin to induce hypoglycemia combined with reduced doses of chemotherapy over an 8-month period. For each treatment, insulin at $0.2 \mathrm{U} / \mathrm{kg}$ body weight was injected intravenously (i.v.), and when blood glucose level reached 2.5-3.0 mmol/1, navelbine $(10 \mathrm{mg})$, cisplatin (10 mg) and fluorouracil (250 mg) were injected (i.v.) over a period of $\sim 10 \mathrm{~min}$. The patient's blood glucose level
\end{abstract}

Correspondence to: Dr Yongping Liu, Clinical Oncology Laboratory, Changzhou Tumor Hospital Affiliated to Soochow University, 68 Honghe Road, Changzhou, Jiangsu 213032, P.R. China E-mail: liuyongping026@126.com

Key words: glucose inhibition, non-small cell lung cancer, adenosine triphosphate, Warburg effect was returned to normal immediately after chemotherapy with an i.v. injection of $20 \mathrm{ml} \mathrm{50 \%} \mathrm{glucose} \mathrm{solution.} \mathrm{During} \mathrm{the}$ 8-month chemotherapy regimen, the patient received two PET/CT follow-ups. The results demonstrated that the levels of ${ }^{18} \mathrm{~F}-\mathrm{FDG}$ uptake in all lesions had been reduced. In addition, the patient exhibited improved appetite and weight gain, a reduced cough, and had less pain. The levels of tumor markers, namely carcinoembryonic antigen, carcinoma antigen 15-3, CYRA21-1, neuron-specific enolase, also declined gradually. These results suggest that controlled, mild hypoglycemia may be safely combined with low dose chemotherapy to provide clinical benefit for advanced non-small cell lung cancer.

\section{Introduction}

Among patients with lung cancer, 30-40\% develop bone metastases (1), while 40-50\% develop brain metastases $(2,3)$. The median overall survival (OS) rate of these patients with brain metastases is $<1$ year (3). Current therapeutic approaches for cancer bone and brain metastasis include palliative radiotherapy and systemic therapy with chemotherapy and targeted agents $(3,4)$. Platinum-based combination chemotherapy is the standard of care for non-small cell lung cancer (NSCLC) (5); however, drug resistance limits the therapeutic efficacy of combination chemotherapy in advanced NSCLC (6). Among the key mechanisms by which cancer cell acquire multi-drug resistance is the upregulation of adenosine triphosphate (ATP)-binding cassette $(\mathrm{ABC})$ transporters, including P-glycoprotein (ABCB1), breast cancer resistance protein $(\mathrm{ABCG})$ and multi-drug resistance associated protein-1, in order to export a number of different chemotherapeutics from the cytoplasm (7). The concept that cancer stem cells may originate from a fusion between an 'altered' pre-malignant cell and a bone marrow-derived stem cell has been proposed (8). Numerous studies have observed higher expression of $\mathrm{ABC}$ transporters in cancer stem cells and significant associations of cancer stem cells with multi-drug resistance and tumor relapse (9-12). ABC transporter activity is dependent on ATP (13) and cancer cells produce ATP primarily through glycolysis, even under normal oxygen concentrations, in a process of anaerobic glycolysis known as the 'Warburg effect' $(14,15)$. 
Anaerobic glycolysis produces only two ATPs per glucose molecule and is less efficient than oxidative phosphorylation, which produces $\sim 38$ ATPs per glucose molecule $(16,17)$. This suggests that tumor cells require a larger supply of glucose compared with normal cells. Therefore, it was hypothesized that brief and mild induction of hypoglycemia during chemotherapy may increase the sensitivity of cancer cells to chemotherapeutic agents, which may thus bring palliative benefit to patients with advanced cancers by enabling a decrease in the effective dose of chemotherapeutic drugs. The present report describes an advanced pulmonary adenocarcinoma patient with multiple bone and brain metastases who received treatments of insulin-induced hypoglycemia followed by reduced doses of chemotherapy. The study was approved by the Ethics Committee of Changzhou Tumor Hospital (Changzhou, China) and the patient provided written informed consent.

\section{Case report}

A 64-year-old male was referred to the Department of Medical Oncology at Changzhou Tumor Hospital (Changzhou, China) in May 2013 for advanced pulmonary adenocarcinoma with multiple bone metastases. Two months prior, the patient presented with mild coughing and pain in the lower back at a local hospital. During this initial visit, a computed tomography (CT) scan revealed a mass in the upper right lung and mediastinal and right hilar lymph node enlargement. Adenocarcinoma cancer cells were detected by fiber bronchoscope examination and cytological examination. A whole body radionuclide bone scan identified increased radiation uptake in multiple bones, suggesting widespread bone metastases. After 2 cycles of systemic chemotherapy (cisplatin $75 \mathrm{mg} / \mathrm{m}^{2}$ and pemetrexed $500 \mathrm{mg} / \mathrm{m}^{2}$ on day 1 of a 3 -week cycle) at the local hospital, the patient experienced no marked relief of the bone pain or irritable cough. The patient was prescribed tramadol $(100 \mathrm{mg}$; PO q12h) to ease the pain. The serum concentration of carcinoembryonic antigen (CEA) increased from $456.7 \mathrm{ng} / \mathrm{ml}$ on first admission to $>1,000 \mathrm{ng} / \mathrm{ml}$ following chemotherapy.

On admission to Changzhou Tumor Hospital, the patient complained of whole body bone pain, an irritating cough, poor appetite, fatigue and substantial weight loss experienced for $\sim 2$ months. Prior to chemotherapy, the patient exhibited adequate parameters of organ function, as follows: Adequate bone marrow reserve [white blood cell count, $>4,000 / \mathrm{ml}$ (reference range, 4,000-10,000/ml), platelet count, $>100,000 / \mathrm{ml}$ (reference range, 100,000-300,000/ml)]; absence of heart disease and heart rate, $69 \mathrm{bpm}$ [reference range, 60-100 bpm (18)]; serum creatinine, $49.3 \mu \mathrm{mol} / 1$ (reference range, $45-84 \mu \mathrm{mol} / \mathrm{l}$ ); serum bilirubin and alanine aminotransferase, $7.8 \mu \mathrm{mol} / 1$ and $15 \mathrm{U} / 1$, respectively (reference ranges, 1.7-23.9 $\mu \mathrm{mol} / 1$ and 13-35 U/1, respectively). References ranges were according to manufacturer's guidelines unless otherwise stated. The baseline levels of serum tumor markers prior to chemotherapy are presented in Table I. For measurement of the serum tumor markers CEA, carcinoma antigen 15-3 (CA 15-3), CYFRA21-1 and neuron-specific enolase (NSE), peripheral blood $(2.0 \mathrm{ml})$ was collected in a vacuum tube (BD Biosciences, Franklin Lakes, NJ, USA) without hematolysis or lipemia from each participant following overnight fasting.
Each sample was centrifuged at $1,710 \mathrm{x}$ g for $5 \mathrm{~min}$ at $4^{\circ} \mathrm{C}$. The serum was retained following centrifugation, and kept at $4^{\circ} \mathrm{C}$ until analysis. The assays were performed within 5 days after samples acquisition. Electrochemiluminescence immunization with an immunology analyzer (Roche Cobas e601; Roche Diagnostics, Basel, Switzerland) was performed to evaluate the tumor markers (19). All tumor marker detection kits were purchased from Roche Diagnostics. According to the manufacturer's recommendations, the reference values of the markers were as follows: CEA, $<5.0 \mathrm{ng} / \mathrm{ml}$; CA 15-3, $<39 \mathrm{U} / \mathrm{ml}$; CYFRA21-1, $<3.3 \mathrm{ng} / \mathrm{ml}$; and NSE, $<17.0 \mathrm{ng} / \mathrm{ml}$.

To prepare for chemotherapy combined with glucose inhibition, the patient fasted after $10 \mathrm{pm}$ on the day before chemotherapy to achieve a consistent blood glucose level, though was allowed to drink water. On each day of chemotherapy, the baseline blood glucose levels were tested with a glucometer (SD Codefree; SD BioSensor, Inc., Suwon, South Korea) using standard procedures described by the manufacturer, and the range was determined to be 4.5-5.4 mmol/1 [reference range, $\leq 6.1 \mathrm{mmol} / 1$ (20)]. Subsequently, insulin (Nanjing Xinbai Pharmaceutical Co., Ltd., Nanjing, China) at $0.2 \mathrm{U} / \mathrm{kg}$ body weight was administered to the patient intravenously (i.v.). After $20 \mathrm{~min}$, when the blood glucose levels had dropped to $2.5-3.0 \mathrm{mmol} / \mathrm{l}$, chemotherapy was initiated, namely through sequential i.v. injections of navelbine (10 mg; Jiangsu Hengrui Medicine Co., Ltd., Lianyungang, China), cisplatin $(10 \mathrm{mg})$ and fluorouracil $(250 \mathrm{mg}$; both from Qilu Pharmaceutical Co., Ltd., Jinan, China) administered over $\sim 10$ min. Following chemotherapy on all treatment days, blood glucose level dropped to $1.6-2.5 \mathrm{mmol} / 1$, and was subsequently elevated to $7-9 \mathrm{mmol} / \mathrm{l}$ by i.v. injection with $20 \mathrm{ml} \mathrm{50 \%} \mathrm{glucose.} \mathrm{Following} \mathrm{each} \mathrm{round} \mathrm{of} \mathrm{treatment,}$ the patient was able to eat a full meal. The chemotherapy treatments were administered 7 times/month for 8 months (56 rounds in total). During each treatment, the patient experienced only mild discomforts of mild heart palpitations and increased sweating. Following the treatments, the patient generally experienced an increase in appetite but no nausea or vomiting. Additionally, the patient's heart rate (69-96 bpm) and blood pressure [90/60-130/88 $\mathrm{mmHg}$; reference range, $90 / 60-140 / 90 \mathrm{mmHg}(21)]$ changed little throughout the induced changes in blood glucose levels.

After 3 rounds of chemotherapy, the patient noted a reduction in pain levels. After 2 months, the patient noted an obvious reduction in coughing. After $\sim 4$ months, the patient's weight increased from $58 \mathrm{~kg}$ (measured on admission) to $63 \mathrm{~kg}$. The serum levels of tumor markers also generally declined gradually (Table I). During the 56 rounds of chemotherapy, the patient presented with grade 1 anemia once following the fifth cycle of chemotherapy, with a serum hemoglobin $(\mathrm{Hb})$ concentration of $110 \mathrm{~g} / \mathrm{l}$ [reference range of serum $\mathrm{Hb}$ concentration in males, 131-172 g/l (22)].

A metabolic response assessment with F-18 fluorodeoxy glucose $\left({ }^{18} \mathrm{~F}-\mathrm{FDG}\right)$ positron emission tomography (PET; Infinia vc Hawkeye 4; GE Healthcare, Chicago, IL, USA) (23) and a brain metastases response assessment with magnetic resonance imaging (MRI; Magnetom Trio; Siemens Healthineers, Erlangen, Germany) (24) were performed on the patient. A baseline ${ }^{18} \mathrm{~F}-\mathrm{FDG}$ PET/CT scan prior to the start of chemotherapy (Fig. 1) identified increased ${ }^{18} \mathrm{~F}-\mathrm{FDG}$ uptake 
Table I. Changes in the serum levels of tumor markers during chemotherapy.

Tumor markers

\begin{tabular}{lrrrr}
\cline { 2 - 5 } Chemotherapy cycle & CEA $(\mathrm{ng} / \mathrm{ml})$ & CA 15-3 $(\mathrm{U} / \mathrm{ml})$ & CYRA21-1 (ng/ml) & NSE $(\mathrm{ng} / \mathrm{ml})$ \\
\hline Baseline & $>1,000.0$ & 159.7 & 165.0 & 35.6 \\
Second & $>1,000.0$ & 121.8 & 5.5 & 24.0 \\
Third & $>1,000.0$ & 97.9 & 3.6 & 15.0 \\
Fourth & $>1,000.0$ & 74.7 & 2.8 & 12.1 \\
Fifth & 941.6 & 50.0 & 2.5 & 10.1 \\
Sixth & 747.5 & 48.0 & 1.6 & 10.2 \\
Seventh & 721.8 & 43.4 & 1.2 & 10.0 \\
Eighth & 395.3 & 41.8 & & \\
\hline
\end{tabular}

Tumor markers were measured prior to each chemotherapy cycle. Data are presented as single measurements. CEA, carcinoembryonic antigen; CA 15-3, carcinoma antigen 15-3; NSE, neuron-specific enolase.

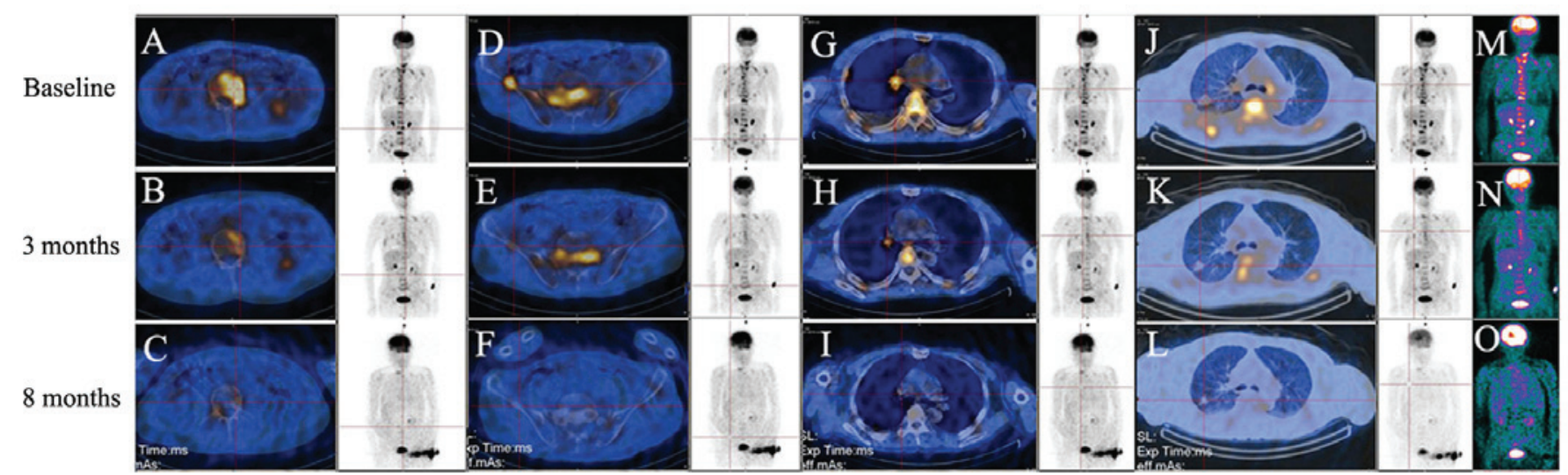

Figure 1. (A-O) ${ }^{18} \mathrm{~F}$-FDG PET/CT scans. Equivalent full body images on each row are shown. To indicate the changes in ${ }^{18} \mathrm{~F}$-FDG uptake, areas of lesions (red intersections) with increased ${ }^{18} \mathrm{~F}$-FDG uptake are displayed. A baseline ${ }^{18} \mathrm{~F}-\mathrm{FDG}$ PET/CT scan prior to the start of chemotherapy identified increased ${ }^{18} \mathrm{~F}$-FDG uptake in multiple bones (A, lumbar; D, right iliac crest; M, colored full body image), in (G) the right hilum and in (J) the right upper lung. Following chemotherapy treatments, ${ }^{18} \mathrm{~F}$-FDG PET/CT scans identified gradually reduced ${ }^{18} \mathrm{~F}$-FDG uptake in all the above lesions after 3 months $(\mathrm{B}, \mathrm{E}, \mathrm{H}, \mathrm{K}$ and $\mathrm{N})$ and 8 months (C, F, I, L and O) of chemotherapy treatments. ${ }^{18} \mathrm{~F}-\mathrm{FDG}$ PET/CT, F-18 fluorodeoxy glucose positron electron tomography/computed tomography.

in the right hilum, right upper lung, shoulder blades, thoracic vertebrae, lumbar, sacrum, bilateral iliac crest and pelvis, and the largest tumor-to-normal $(\mathrm{T} / \mathrm{N})$ ratio was 9.1 [normal T/N range, $\leq 1.0$ (23)] in the lumbar, which indicated increased glucose metabolism in the tumor regions. After $\sim 4$ months of chemotherapy, ${ }^{18} \mathrm{~F}-\mathrm{FDG}$ PET/CT exhibited decreased ${ }^{18} \mathrm{~F}-\mathrm{FDG}$ uptake in the same lesions (Fig. 1). ${ }^{18} \mathrm{~F}-\mathrm{FDG}$ uptake was further decreased after $\sim 8$ months, and the greatest $\mathrm{T} / \mathrm{N}$ ratio (9.1) had decreased to 1.0 , which was paralleled by a reduction in the size of the right upper lung lesion (Fig. 1). Prior to the start of chemotherapy, the head MRI exhibited multiple metastases in the brain, while after 4 months of chemotherapy, MRI identified reductions in the volumes of the brain metastases (data not shown).

At $\sim 2$ months after completion of the chemotherapy course, the patient presented with changes in his emotional state, and although the volumes of the brain metastases had been obviously reduced, MRI identified widespread soft meningeal metastases. Testing of bronchoscopy biopsy tissue for epidermal growth factor (EGFR) mutation by direct sequencing (Applied Biosystems; Thermo Fisher Scientific,
Inc., Waltham, MA, USA) indicated that the patient harbored EGFR exon 21 heterozygous mutations (data not shown), and thus was eligible to receive tyrosine kinase inhibitor (TKI) treatment. The patient received whole brain radiotherapy (doses and schedule unknown) followed by TKI treatment (gefitinib, $250 \mathrm{mg} /$ day; AstraZeneca, Cambridge, UK) for $\sim 8$ months at the initial local hospital. However, the patient finally succumbed due to meningeal metastasis. The progression-free survival following glucose inhibition combined with chemotherapy was about 11 months, and the OS rate following all treatments was 25 months.

\section{Discussion}

Increased activity of drug efflux pumps, including of the ABC superfamily, is considered to be critical in removing chemotherapeutic agents from cancer cells and causing chemotherapy failure (7). The activity of drug efflux pumps is dependent on ATP hydrolysis, and cancer cells produce ATP primarily through glycolysis, even under normal oxygen concentrations (the Warburg effect) $(14,15)$. Thus, inhibition of tumor 
glycolysis may impact tumor growth by depleting cellular energy, and may be particularly effective when combined with cancer cell sensitization to therapeutic drugs (25-27). A number of glycolytic inhibitors that target the glycolytic enzymes have been tested, and may be feasible approaches for targeting the limited metabolic behaviors of cancer cells (28-30). Although targeting glucose metabolism seems a viable strategy for cancer therapy, the potential toxic effects of inhibiting metabolic enzymes on normal cells need to be determined in future studies. Distant solid tumor metastases are generally characterized by markedly increased glycolytic activity compared with primary solid tumors, and cancer cells in metastases are typically more resistant to chemotherapy than primary cancer cells (31). In the present lung cancer patient presenting with widespread bone and brain metastases, the ${ }^{18} \mathrm{~F}-\mathrm{FDG}$ PET/CT scan identified increased ${ }^{18} \mathrm{~F}$-FDG uptake in multiple bones and in the primary lung tumor, indicating increased glucose uptake and thus the presence of cancer cells. Meanwhile, the head MRI detected multiple metastases in the brain. It was hypothesized that a brief reduction in blood sugar levels may cause a reduction in ATP production in cancer cells, which in turn may lead to increased sensitivity of the cancer cells to lower dose chemotherapy agents. The present case report first confirmed that a $10-15$ min periods of controlled hypoglycemia (1.6-3.0 mmol/l) was safe. During hypoglycemia, the patient experienced only mild heart palpitations and increases in sweating, and when blood glucose levels were returned to normal range with $20 \mathrm{ml} 50 \%$ glucose solution (i.v.), the patient recovered from the hypoglycemic symptoms. Secondly, administering reduced doses of chemotherapeutics during mild hypoglycemia was an effective treatment method for the patient with advanced lung cancer. The ${ }^{18} \mathrm{~F}-\mathrm{FDG}$ PET/CT scans taken every 3-5 months demonstrated that glucose uptake in the tumor lesions was gradually reduced during the chemotherapy course. Notably, PET/CT scan following completion of the chemotherapy course indicated that glucose uptake values in all cancer lesions were almost equivalent to those in adjacent normal tissues. After 4 months of chemotherapy, the MRI identified decreased tumor volumes of the brain metastases. Furthermore, the patient noted pain relief and his cough was alleviated. His appetite also increased, his weight increased from 58 to $63 \mathrm{~kg}$, and nausea and vomiting were absent.

Bone and brain metastases are highly common secondary localizations of disease in patients with lung cancer, and are associated with substantial negative effects on patient quality of life and survival (1,3). The median survival time of patients with these secondary lesions has been reported as 3-7 months (32-34), and the patients frequently require therapeutic intervention. Zoledronic acid is the first and seemingly only bisphosphonate that has exhibited efficacy in the treatment of bone metastases in a randomized phase III trials $(35,36)$. Previous treatments for brain metastases have focused on symptom palliation with whole brain radiotherapy and steroids (3). The TKIs, gefitinib and erlotinib, are also effective options for the treatment of bone and brain metastases, particularly in patients with EGFR mutation (37). Despite advances in the targeted treatment of NSCLC over past years, chemotherapy remains of key importance in the treatment of advanced NSCLC. Platinum-based combination chemotherapy has been a standard of treatment for metastatic
NSCLC for more than 30 years, though reaches a therapeutic plateau (3). Therefore, there has been focus on the combination of novel agents with chemotherapy to optimize efficacy, patient survival and overcome acquired resistance (38). It has been proposed that insulin as a pharmacological agent induces a switch from a non-cycling to cycling status in tumor cells (39), thus increasing the uptake of chemotherapeutic agents (40) and their cytotoxic effect in cancer cells (41). In the current patient, insulin-induced hypoglycemia followed by reduced-dose chemotherapy drugs was observed to reduce the glucose uptake and sizes of metastatic tumor lesions, and to improve the patient's quality of life, notably by reducing bone pain and analgesic use, improving appetite and increasing body weight. It may be speculated that hypoglycemia inactivates ABC transporter pump activity, particularly in cancer cells due to the Warburg effect. This may cause increased accumulation of chemotherapeutic agents in cancer cells. However, further experiments are required to verify these mechanisms. From the current treatment study, it may be proposed that insulin-induced hypoglycemia followed by low dose chemotherapy is a viable choice for the palliative care of patients with advanced solid tumors, particularly of those patients who can not tolerate or have failed traditional chemotherapy regimens. Future studies of similar cases are now required to validate the feasibility of this treatment method.

\section{Acknowledgements}

The authors would like to thank personnel at the Changzhou Tumor Hospital (Changzhou, China) who were involved in the present study, and Dr Tom C. Tsang (Arizona Cancer Center, University of Arizona, Tucson, USA) for his advice on treatment. The present study was supported by the Science and Technology Planning Project of Changzhou, Jiangsu Province (grant no. CE20165052), the Science and Technology Planning Project of Changzhou Health Bureau (grant no. ZD201616), the Research Project of the Health Department of Jiangsu Province (grant no. Z201616), the 333 Talents Training Project of Jiangsu Province (grant no. 2016 III-0727; BRA2017114) and the Key Medical Innovation Talents Training Project of Changzhou (grant no. 2016CZLJ021). The abstract was presented at the 24th Biennial Congress of the European Association for Cancer Research July 9-12, 2016 in Manchester, UK and published as abstract no. 899 in European Journal of Cancer 61 (Suppl 1), 2016.

\section{References}

1. Tsuya A, Kurata T, Tamura K and Fukuoka M: Skeletal metastases in non-small cell lung cancer: A retrospective study. Lung Cancer 57: 229-232, 2007.

2. Mamon HJ, Yeap BY, Jänne PA, Reblando J, Shrager S, Jaklitsch MT, Mentzer S, Lukanich JM, Sugarbaker DJ, Baldini EH, et al: High risk of brain metastases in surgically staged IIIA non-small-cell lung cancer patients treated with surgery, chemotherapy, and radiation. J Clin Oncol 23: 1530-1537, 2005.

3. Lemjabbar-Alaoui H, Hassan OU, Yang YW and Buchanan P: Lung cancer: Biology and treatment options. Biochim Biophys Acta 1856: 189-210, 2015.

4. Owonikoko TK, Arbiser J, Zelnak A, Shu HK, Shim H, Robin AM, Kalkanis SN, Whitsett TG, Salhia B, Tran NL, et al: Current approaches to the treatment of metastatic brain tumours. Nat Rev Clin Oncol 11: 203-222, 2014. 
5. Rossi A, Chiodini P, Sun JM, O'Brien ME, von Plessen C, Barata F, Park K, Popat S, Bergman B, Parente B, et al: Six versus fewer planned cycles of first-line platinum-based chemotherapy for non-small-cell lung cancer: A systematic review and meta-analysis of individual patient data. Lancet Oncol 15 1254-1262, 2014.

6. Leon G, MacDonagh L, Finn SP, Cuffe S and Barr MP: Cancer stem cells in drug resistant lung cancer: Targeting cell surface markers and signaling pathways. Pharmacol Ther 158: 71-90, 2016.

7. Gottesman MM, Fojo T and Bates SE: Multidrug resistance in cancer: Role of ATP-dependent transporters. Nat Rev Cancer 2: 48-58, 2002.

8. He X, Tsang TC, Pipes BL, Ablin RJ and Harris DT: A stem cell fusion model of carcinogenesis. J Exp Ther Oncol 5: 101-109, 2005.

9. Castillo V, Valenzuela R, Huidobro C, Contreras HR and Castellon EA: Functional characteristics of cancer stem cells and their role in drug resistance of prostate cancer. Int J Oncol 45 : 985-994, 2014

10. Wu C and Alman BA: Side population cells in human cancers. Cancer Lett 268: 1-9, 2008.

11. Haraguchi N, Utsunomiya T, Inoue H, Tanaka F, Mimori K, Barnard GF and Mori M: Characterization of a side population of cancer cells from human gastrointestinal system. Stem Cells 24 506-513, 2006

12. Hirschmann-Jax C, Foster AE, Wulf GG, Nuchtern JG, Jax TW, Gobel U, Goodell MA and Brenner MK: A distinct 'side population' of cells with high drug efflux capacity in human tumor cells. Proc Natl Acad Sci USA 101: 14228-14233, 2004.

13. Fletcher JI, Haber M, Henderson MJ and Norris MD: ABC transporters in cancer: More than just drug efflux pumps. Nat Rev Cancer 10: 147-156, 2010.

14. Epstein T, Xu L, Gillies RJ and Gatenby RA: Separation of metabolic supply and demand: Aerobic glycolysis as a normal physiological response to fluctuating energetic demands in the membrane. Cancer Metab 2: 7, 2014.

15. Thorne JL and Campbell MJ: Nuclear receptors and the Warburg effect in cancer. Int J Cancer 137: 1519-1527, 2015.

16. Gatenby RA and Gillies RJ: A microenvironmental model of carcinogenesis. Nat Rev Cancer 8: 56-61, 2008.

17. Rich PR: The molecular machinery of Keilin's respiratory chain Biochem Soc Trans 31: 1095-1105, 2003.

18. Magder SA: The ups and downs of heart rate. Crit Care Med 40 239-245, 2012

19. Zhao W, Yu H, Han Z, Gao N, Xue J and Wang Y: Clinical significance of joint detection of serum CEA, SCCA, and bFGF in the diagnosis of lung cancer. Int J Clin Exp Pathol 8 : 9506-9511, 2015

20. Shaye K, Amir T, Shlomo S and Yechezkel S: Fasting glucose levels within the high normal range predict cardiovascular outcome. Am Heart J 164: 111-116, 2012.

21. Frese EM,Fick A and Sadowsky HS: Blood pressure measurement guidelines for physical therapists. Cardiopulm Phys Ther J 22 $5-12,2011$

22. Wu X, Zhao M, Pan B, Zhang J, Peng M, Wang L, Hao X, Huang X, Mu R, Guo W, et al: Complete blood count reference intervals for healthy Han Chinese adults. PLoS One 10: e0119669, 2015.

23. Wang P, Meng Z, Tan J, Jia Q and Zhang F: An improved method for measurement of target-to-background ratio in assessing mediastinal lesions on ${ }^{18} \mathrm{~F}$-FDG coincidence SPECT/CT imaging. Nucl Med Commun 31: 398-404, 2010.

24. Noebauer-Huhmann IM, Szomolanyi P, Kronnerwetter C, Widhalm G, Weber M, Nemec S, Juras V, Ladd ME, Prayer D and Trattnig S: Brain tumours at 7T MRI compared to 3T--contrast effect after half and full standard contrast agent dose: Initial results. Eur Radiol 25: 106-112, 2015.
25. Hsu PP and Sabatini DM: Cancer cell metabolism: Warburg and beyond. Cell 134: 703-707, 2008

26. Dang CV, Hamaker M, Sun P, Le A and Gao P: Therapeutic targeting of cancer cell metabolism. J Mol Med (Berl) 89: 205-212, 2011.

27. Birsoy K, Sabatini DM and Possemato R: Untuning the tumor metabolic machine: Targeting cancer metabolism: A bedside lesson. Nat Med 18: 1022-1023, 2012.

28. Rosano C: Molecular model of hexokinase binding to the outer mitochondrial membrane porin (VDAC1): Implication for the design of new cancer therapies. Mitochondrion 11: 513-519, 2011

29. Jae HJ, Chung JW, Park HS, Lee MJ, Lee KC, Kim HC, Yoon JH, Chung $\mathrm{H}$ and Park JH: The antitumor effect and hepatotoxicity of a hexokinase II inhibitor 3-bromopyruvate: In vivo investigation of intraarterial administration in a rabbit VX2 hepatoma model. Korean J Radiol 10: 596-603, 2009.

30. Wallace DC: Mitochondria and cancer: Warburg addressed. Cold Spring Harb Symp Quant Biol 70: 363-374, 2005.

31. Winquist RJ, Boucher DM, Wood M and Furey BF: Targeting cancer stem cells for more effective therapies: Taking out cancer's locomotive engine. Biochem Pharmacol 78: 326-334, 2009.

32. Patchell RA, Tibbs PA, Regine WF, Dempsey RJ, Mohiuddin M, Kryscio RJ, Markesbery WR, Foon KA and Young B: Postoperative radiotherapy in the treatment of single metastases to the brain: A randomized trial. JAMA 280: 1485-1489, 1998.

33. Patchell RA, Tibbs PA, Walsh JW, Dempsey RJ, Maruyama Y, Kryscio RJ, Markesbery WR, Macdonald JS and Young B: A randomized trial of surgery in the treatment of single metastases to the brain. N Engl J Med 322: 494-500, 1990.

34. Coleman RE: Metastatic bone disease: Clinical features, pathophysiology and treatment strategies. Cancer Treat Rev 27: 165-176, 2001.

35. Rosen LS, Gordon D, Tchekmedyian S, Yanagihara R, Hirsh V, Krzakowski M, Pawlicki M, de Souza P, Zheng M, Urbanowitz G, et al: Zoledronic acid versus placebo in the treatment of skeletal metastases in patients with lung cancer and other solid tumors: A phase III, double-blind, randomized trial - the Zoledronic Acid Lung Cancer and Other Solid Tumors Study Group. J Clin Oncol 21: 3150-3157, 2003

36. Rosen LS, Gordon D, Tchekmedyian NS, Yanagihara R, Hirsh V, Krzakowski M, Pawlicki M, De Souza P,Zheng M, Urbanowitz G, et al: Long-term efficacy and safety of zoledronic acid in the treatment of skeletal metastases in patients with nonsmall cell lung carcinoma and other solid tumors: A randomized, phase III, double-blind, placebo-controlled trial. Cancer 100: 2613-2621, 2004.

37. Masters GA, Temin S, Azzoli CG, Giaccone G, Baker S Jr, Brahmer JR, Ellis PM, Gajra A, Rackear N, Schiller JH, et al; American Society of Clinical Oncology Clinical Practice: Systemic therapy for stage IV non-small-cell lung cancer: American Society of Clinical Oncology Clinical Practice Guideline Update. J Clin Oncol 33: 3488-3515, 2015.

38. Belani CP: Optimizing chemotherapy for advanced non-small cell lung cancer: Focus on docetaxel. Lung Cancer 50 (Suppl 2): 3-8, 2005 .

39. Gross GE, Boldt DH and Osborne CK: Perturbation by insulin of human breast cancer cell cycle kinetics. Cancer Res 44: 3570-3575, 1984.

40. Oster JB and Creasey WA: Enhancement of cellular uptake of ellipticine by insulin preincubation. Eur J Cancer Clin Oncol 17 1097-1103, 1981

41. Alabaster O, Vonderhaar BK and Shafie SM: Metabolic modification by insulin enhances methotrexate cytotoxicity in MCF-7 human breast cancer cells. Eur J Cancer Clin Oncol 17: $1223-1228,1981$ 